\title{
Review Article \\ Medicinal Effect of Nutraceutical Fruits for the Cognition and Brain Health
}

\author{
Raj K. Keservani, ${ }^{1}$ Anil K. Sharma, ${ }^{2}$ and Rajesh K. Kesharwani ${ }^{3}$ \\ ${ }^{1}$ School of Pharmaceutical Sciences, Rajiv Gandhi Proudyogiki Vishwavidyalaya, Bhopal 462036, India \\ ${ }^{2}$ Department of Pharmaceutics, Delhi Institute of Pharmaceutical Sciences and Research, New Delhi 110017, India \\ ${ }^{3}$ Department of Biotechnology, NIET, NIMS University, Shobha Nagar, Jaipur, Rajasthan 303121, India \\ Correspondence should be addressed to Raj K. Keservani; rajksops@gmail.com
}

Received 3 December 2015; Revised 15 January 2016; Accepted 20 January 2016

Academic Editor: Farrukh Afaq

Copyright ( 92016 Raj K. Keservani et al. This is an open access article distributed under the Creative Commons Attribution License, which permits unrestricted use, distribution, and reproduction in any medium, provided the original work is properly cited.

\begin{abstract}
The recent era is witnessing evaluation of medicinal and nutritional value of fruits and fruit juices for the management and prevention of brain diseases like headache stress, anxiety, hypertension, and Alzheimer's and Parkinson's diseases by the scientists and researchers worldwide. Fruits possess various chemicals such as antioxidants and polyphenols, which reduce and balance the effect of hormone in brain responsible for brain disease. Natural remedy is cheap, easily available, nontoxic, and easy to prepare and provides good mental health as compared to other remedies. The main objective of this review is to acknowledge medicinal benefits of fruits for the cognition and management of brain disease.
\end{abstract}

\section{Introduction}

The potential of food as prophylactic and therapeutic agent versus diseases has now begun to be acknowledged. The fascinating facts have been revealed about effect of dietary factors on certain molecular systems and mechanisms that take care of mental activity in recent years. A diet that is high in omega-3 fatty acids is earning accolades for reinforcing cognitive activity in humans [1] and upregulating genes that are vital for sustaining synaptic activity and agility in rodents [2]. Eventually, diets that are rich in saturated fat are turning culprits for lowering molecular scaffolds that help cognitive function and elevating the danger of neurological dysfunction in humans [3] as well as animals [4]. Thus, a combination of nutrition and exercise is recommended to undo these probable ill health outcomes. This is further corroborated by information available in the literature [5].

Nutraceutical is hybrid of nutrition and pharmaceutical and was introduced in 1989 by Stephen L. DeFelice, founder and chairperson of the Foundation of Innovation Medicine, and defined as "Food, or parts of food, that provide medical or health benefits, including the prevention and treatment of disease" $[6,7]$. Functional foods, according to their generally accepted definition, are "any food or food ingredient that may provide a health benefit beyond the traditional nutrients it contains" [8]. Plenty of studies are about fruitful influences of nutraceuticals like antioxidant, mushrooms, vitamins, essential amino acids, phytochemicals, and polyunsaturated fatty acids in pediatric foods upon the budding immune response $[7,9]$.

There are numerous evidences regarding effect of general physical condition on children's cognitive ability and school performance $[10,11]$. The activity of brain is definitely based on appropriate nutrition, and short-term alterations in the quantity and makeup of nutrient intake in healthy individuals affect actions of cognitive processes. It has been observed that consuming breakfast leads to a number of affirmative influences on the cognitive activity of well-fed children [11, 12]. The elevated hormone content and enzyme functions signal towards sensitivity of brain for stress [13]. The high stress circumstances may trigger depression and in adverse manner alter behavioral, learning, and biochemical activities. A mood disorder such as major depression is probable life endangering disease. A sizeable population of patients with depression is reckoned to be treatment resistant even after advancement of pharmacotherapy [14]. The antidepressant 
drugs suffer from drawbacks such as postcompliance side effects or absence of required effect $[15,16]$. These findings have ignited the minds of researchers to pursue hunt for natural remedies for improved beneficial effects with no or lesser toxic consequences. The dementia is often manifested by Alzheimer's disease. It causes severe suffering for the patients, in the form of progressive behavioral and neurological changes that include functional impairment, loss of independency, emotional problems, and behavioral disturbances [17].

A high risk of many mental disorders has been observed, such as attention-deficit disorder, dyslexia, dementia, depression, bipolar disorder, and schizophrenia when humans are omega-3 fatty acids deficient [18-22]. Since the human body is not able to synthesize omega-3 fatty acid docosahexaenoic acid (DHA) that is an important part of neuronal membranes, we have to depend on DHA from dietary sources. The mechanisms underlying DHA's action on brain plasticity and cognition have begun to be explained in recent times. The enhancement of hippocampal brain-derived neurotrophic factor (BDNF) content and increased cognitive process in rodent models of brain trauma are observed during DHA dietary supplementation [23].

\section{Nutraceutical Fruits for Cognition and Brain Health}

Fruits and fruit juice were used for cognition and brain health. Keservani and coworkers reported the use of various fruits for brain health because of medicinal value of fruits [24, 25]. Keservani and Sharma reported the role of vitamin C and polyphenols found in citrus fruits and blueberries in mental performance [26]. Detailed description of blackberries, blueberries, strawberries, raspberries, cherries, oranges, plums, prunes, red grapes, and pomegranates fruits is mentioned in the following sections. The numerous phytochemicals occurring in these fruits are listed in Table 1 and their structures are depicted by Figure 1.

2.1. Blackberries. Several species in the Rubus genus of Rosaceae family, hybrids of these species in the Rubus subgenus, and hybrids between the Rubus and Idaeobatus subgenera provide blackberry (Figure 2(a)) which is an edible fruit [27]. Blackberries are noteworthy, as these possess rich nutritional amounts of dietary fiber, vitamin C, and vitamin K. Blackberries contain soluble as well as insoluble fiber. The half of the daily recommended dose of vitamin $\mathrm{C}$ may be provided by 1 cup of blackberries ( $144 \mathrm{~g}$ ) which contain a mean of $7.6 \mathrm{~g}$ of fiber.

By virtue of having high polyphenol and anthocyanin content (often collectively known as phytochemicals) red and dark colored berries offer health benefits which are documented too. Nevertheless, researchers around the globe persist to express interest in this region. There has been initial research with focus on the phytochemical makeup of new and much exotic fruits and their comparison with known relatives, berries. A review written by Dr. Miller and Shukitt-Hale of the United States Department of Agriculture
TABLE 1: Various phytoconstituents present in fruits.

\begin{tabular}{ll}
\hline Fruits & Phytochemical compounds \\
\hline Strawberries & $\begin{array}{l}\text { Kaempferol, fisetin, matairesinol, } \\
\text { secoisolariciresinol, gallic acid, ellagic } \\
\text { acid, and chlorogenic acid }\end{array}$ \\
Elackberries & $\begin{array}{l}\text { Ellagic acid } \\
\text { Chlorogenic acid, secoisolariciresinol, } \\
\text { and pterostilbene }\end{array}$ \\
Blueberries & $\begin{array}{l}\text { Ellagic Acid, quercetin, gallic acid, } \\
\text { cyanidins, pelargonidins, catechins, } \\
\text { kaempferol, and salicylic acid }\end{array}$ \\
Raspberries & Lutein, cyanidin \\
Plum & $\begin{array}{l}\text { Lutein, ursolic acid } \\
\text { Prunes }\end{array}$ \\
Cherries & $\begin{array}{l}\text { Rutin, lutein } \\
\text { Oranges }\end{array}$ \\
Red grapes & $\begin{array}{l}\text { Ellagitannins, delphinidin, cyanidin, } \\
\text { pelargonidin glycosides, catechins, } \\
\text { gallocatechins, and prodelphinidins }\end{array}$ \\
\hline
\end{tabular}

(USDA) human nutrition center at Tufts University proposes that intake of blueberries, strawberries, blackberries, and other berry fruits has a valuable effect on the brain and could assist in checking age-linked memory loss and other alterations. The group pleads that the berries possess neuroactive phytochemicals that act as antioxidants as well as anti-inflammatory agents [28].

Berries are famous for their accrual of antioxidant parts (mostly polyphenols, carotenoids, and vitamin C) and for being the fruits offering maximum antioxidant capacity in usually consumed foods [29]. Total polyphenol concentration may also differ at large between berry species and varieties and under different growing environments. Often black currant, raspberry, and strawberry contain total polyphenol amounts in the range of $300-1000 \mathrm{mg} / 100 \mathrm{~g}$ [30]. Besides, the amounts of these antioxidant substances may be hugely affected by postproduction handling and processing [31]; therefore, their content must be authenticated in any product. Recently the role of polyphenol contents in berry as neuroprotective has been documented [28]. The berry ingredients are suggested to guard against damage caused by reactive oxygen species (ROS), which are identified to have role in the progress of neurological conditions like Alzheimer's disease [32]. An improvement in indices of neuronal process in aged rats was observed upon dietary supplementation with blueberry, cranberry, or black currant fruit for eight weeks [33].

2.2. Blueberries. Blueberries (Figure 2(b)) are perennial flowering plants having indigo colored berries of the section Cyanococcus in the genus Vaccinium (a genus that covers cranberries, bilberries, and gooseberries). Species in the section Cyanococcus are the usual fruits advertised as blueberries and are inhabitant to North America (commercially grown high-bush blueberries were not launched in Europe until the 1930s) [34]. 
<smiles>O=C(O)c1cc(O)c(O)c(O)c1</smiles>

Gallic acid<smiles>O=C(O)c1ccccc1O</smiles>

Salicylic acid<smiles>O=c1c(O)c(-c2ccc(O)cc2)oc2cc(O)cc(O)c12</smiles>

Kaempferol<smiles>Oc1ccc(-c2[o+]c3cc(O)cc(O)c3cc2O)cc1</smiles>

Pelargonidin<smiles>Oc1cc(O)c2cc(O)c(-c3ccc(O)c(O)c3)[o+]c2c1</smiles><smiles>Oc1cc(O)c2c(c1)O[C@H](c1ccc(O)c(O)c1)[C@H](O)C2</smiles>

+ Epicatechin<smiles>O=c1c(O)c(-c2ccc(O)c(O)c2)oc2cc(O)cc(O)c12</smiles>

Quercetin<smiles>[R]c1ccc(/C=C/C(=O)O)cc1[R2]</smiles>

Phenolic acid<smiles>c1ccc(-c2cc3ccccc3o2)cc1</smiles>

Flavonoids<smiles>Oc1ccc(/C=C/c2cc(O)cc(O)c2)cc1</smiles>

Stilbene<smiles>COc1cc(CC(CO)C(CO)Cc2ccc(O)c(CO)c2)ccc1O</smiles>

Lignans

FIGURE 1: Structure of polyphenols found in fruits.

In general, water $(84 \%)$, carbohydrates $(9.7 \%)$, proteins $(0.6 \%)$, and fat $(0.4 \%)$ are principal ingredients of a fresh blueberry. A serving of fresh blueberries $(100 \mathrm{~g})$ is approximated to provide energy amounting to about $192 \mathrm{~kJ}$. Blueberries offer a nice supply of dietary fiber that makes $3-3.5 \%$ of its weight. In addition to the taste, the chief attention in this fruit is because of the fair vitamin C content, as $100 \mathrm{~g}$ of blueberries offers, on average, $10 \mathrm{mg}$ of ascorbic acid, which equals $1 / 3$ of the daily recommended intake $[35,36]$.

More recently, studies addressing the effects of other flavonoid subgroups on human cognition have indicated that both blueberry anthocyanins and cocoa flavanols promote positive effects on cognitive outcomes, especially in aged populations. For example, cocoa flavanols (520-994 mg of total cocoa flavanols) have been shown to enhance cognitive and visual function in healthy young volunteers within $2 \mathrm{~h}$ of intake, specifically in highly effortful/demanding tasks $[37,38]$. On the other hand, long-term supplementation (3 months) with blueberry juice in grown-up adults with slight cognitive destruction yielded working memory improvements and further reduced depressive symptoms [39]. An improved short-term cognitive action with high flavonoid fruit juices, including blueberry juice, was observed in a few trials in geriatric population ( $\leq 15$ participants) $[39,40]$. Corroborating these results, berries are in particular rich in a subclass of flavonoids known as anthocyanidins, which can cross the blood brain barrier and concentrate in regions of learning and memory (e.g., hippocampus) [41].

2.3. Strawberries. The garden strawberry (Figure 2(c)) (or simply strawberry; Fragaria ananassa) is a broadly grown crossbreed species of the genus Fragaria (altogether called as the strawberries) [42]. The garden strawberry was at first reared in Brittany, France, in the 1750s through a cross of Fragaria virginiana from eastern North America and Fragaria chiloensis, which was fetched from Chile by Amédée-François Frézier in 1714. As evident from epidemiological studies 


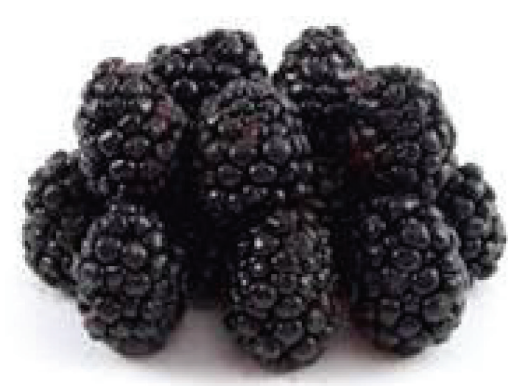

(a)

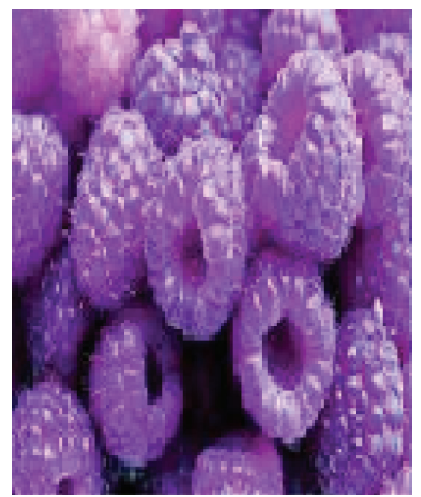

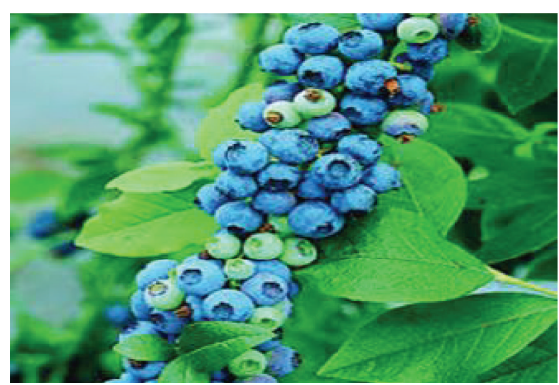

(b)

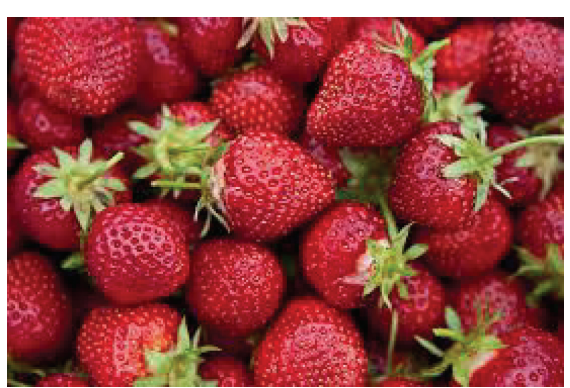

(c)
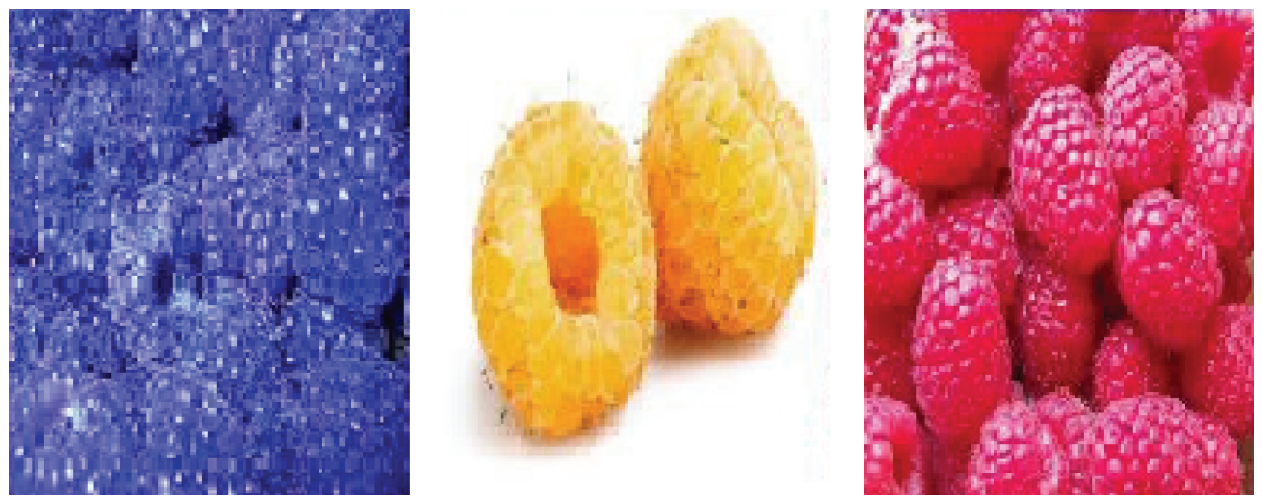

(d)

Figure 2: Structure of nutraceutical fruits for brain health: (a) blackberries, (b) blueberries, (c) strawberries, and (d) raspberries (purple, blue, yellow, and red).

the lower incidences of hypertension, inflammation, cancer, and death from cardiovascular diseases are reported with strawberry consumption [43].

In a study the investigators tested whether long-term (from 6-15 months of age; F344 rats) consumption of a control diet (AIN-93) or a diet supplemented with a strawberry or spinach extract that had been termed as being rich in antioxidant potential by the oxygen radical absorbance capacity assay [44-46] or vitamin E would avert the effects of aging. The diets high in strawberries can also possess the ability to avail benefits to the aging brain, which is exhibited by initial animal studies [47]. Afterwards a number of studies have evaluated the influences of antioxidant and polyphenol high materials on cognitive process. The proofs recommend that these components may certainly affect cognition acutely (when given in high doses) as well as upon long-term intake in both animals and humans [48].

2.4. Raspberries. The raspberry (Figure $2(\mathrm{~d})$ ) is the edible fruit of a large number of plant species in the genus Rubus of the rose family, majority of which are in the subgenus Idaeobatus; the nomenclature is also applicable to such plants themselves. The hybrids between $R$. idaeus and R. strigosus are commercially employed to get red raspberry nowadays. Purple raspberries have been cultivated by horticultural cross of red and black raspberries and have been present in the wild (for instance, in Vermont) where the American red and the black raspberries both grow in nature. Blue raspberry is a vernacular name prevailing in Prince Edward Country, Ontario, Canada. Red raspberries have also been hybridized with different species in other subgenera of the genus Rubus, yielding numerous hybrids; the first of them was the loganberry. Subsequently remarkable crossbreeds encompass boysenberry (a multigeneration hybrid) and tayberry. Further cross between the familiar grown red raspberries and a few Asiatic species of Rubus has also been attempted. Raspberries possess anthocyanin pigments, ellagic acid (from ellagotannins, e.g., the polyphenol ellagitannin), quercetin, gallic acid, cyanidins, pelargonidins, catechins, kaempferol, and salicylic acid $[49,50]$. Yellow raspberries and others having yellow colored fruits are poor in anthocyanins [49]. The yellow as well as red raspberries possess carotenoids, often lutein esters, but these are covered by anthocyanins in red raspberries [51].

The berry ingredients are suggested to guard against damage caused by ROS, which are known to be involved in the progress of neurological diseases like Alzheimer's disease $[28,32]$. The inferences from in vitro investigations have also been exploited to reinforce the probability that polyphenols present in berries may positively remodel amyloidbeta aggregation [52] in vitro, a process that eventually leads to brain damage in Alzheimer's disease. Blueberry extracts defended against damage caused by inflammation of microglial cells via decrease in inflammatory mediators [53]. In a relevant investigation with concord grape juice, which has several polyphenol components, that also occurs in berries, supplementation refined memory behavior in older 


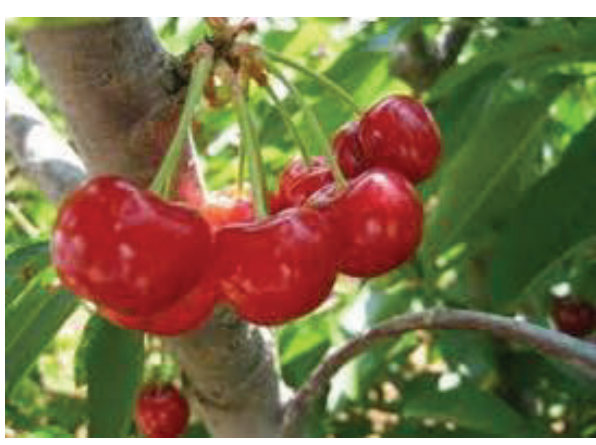

(a)

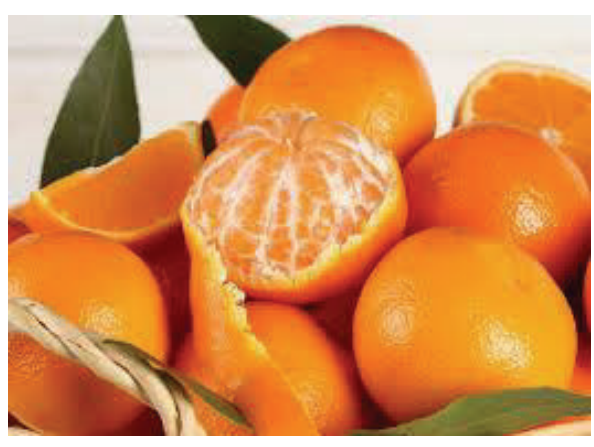

(b)

FIgURE 3: Structure of nutraceutical fruits for brain health: (a) cherries and (b) oranges.

adults with predescribed slight cognitive problems, which was assisted by studies on brain activity employing functional magnetic resonance imaging [54].

2.5. Cherries. The cherry (Figure 3(a)) fruits possessing market value are often procured from restricted types of sources like varieties of the sweet cherry, Prunus avium. Several cherries fall under subgenus Cerasus, which is demarcated by bearing the flowers in tiny corymbs of many in groups (neither alone nor in racemes) and by possessing even fruit having only a faint furrow either with side or without groove [55]. Majority of edible cherries are obtained either from Prunus avium, the sweet cherry (also known as wild cherry), or from Prunus cerasus, the bitter cherry.

There continues to be heightened attention pertaining to application of fruits and vegetables (functional foods) and, in particular, cherries (and other dark fruits) to treat a range of ailments ranging from sleep disorders [56], arthritis [57], muscle damage, and soreness [58] improved cognitive function in Alzheimer's mouse models [59]. The varieties of biological samples have been evaluated for antioxidant activity of cherry extracts. Further, Tsuda et al. [60, 61] exhibited that cyanidin 3-glucoside was found to have best antioxidant activity among the anthocyanins evaluated. The neuronal PC 12 cells subjected to oxidative stress validated antioxidant activity of cherry phenolics [62].

2.6. Oranges. Oranges (Figure 3(b)) are the most famous citrus harvests and make up $75 \%$ of all cultivated citrus fruits. The "Queen" orange [Citrus sinensis (L.) Osb] is cultivated at large scale in Iran. This breed of orange is midseason, of red color, rich in dissolved solids, high in flavor, and seedless to some extent and bears fruits on the tree in a robust manner. The tree is strong, extremely prolific, and immune towards cold [63].

Each $100 \mathrm{~g}$ plateful of orange pulp offers approximately $64 \%$ of vitamin C daily requirements. Several extra vital nutrients are found in low concentrations. A variety of phytochemicals, such as carotenoids (beta-carotene, lutein and beta-cryptoxanthin), flavonoids (e.g., naringenin) [64], and several volatile organic substances giving orange aroma, like aldehydes, esters, terpenes, alcohols, and ketones, are present in orange [65].

The healthy older adults may be benefitted in terms of cognitive function if exclusively orange juice high in flavanone is consumed for 8 weeks. There is need to elucidate mechanisms of decline in cognitive processes upon aging and the influence of foods and drinks high in flavanone [66]. The spinach, orange juice, and yeast are good sources of folate or folic acid. Subsequent to absorption of vitamin B in the intestine, there is production of a number of forms of folate in the liver. Several physiological abnormalities during development and maturity often resulted due to lack of dietary folate intake [67]. Adequate brain functioning warrants optimum amounts of folate as folate deficiency may result in neurological disorders, like depression [68] and cognitive impairment. The age-linked fall in cognitive activity could be checked by intake of folic acid as adjuvant for 3 years as apparent from inferences of latest randomized clinical trial [69].

2.7. Plums. The plum (Figure 4(a)) comes in the subgenus Prunus of the genus Prunus. The subgenus is differentiated from other subgenera (such as peaches, cherries, and bird cherries) in the shoots with a terminal bud and lonely side buds (not grouped), the flowers in bunch of 1-5 together on short stems, and the fruit bearing a furrow along one side and a flat stone (or pit) [70].

Besides berries, the plums are also high at flavonoid content, in particular in anthocyanins, and could be a decent supply of antioxidants from nature [71]. A control over cognitive decline was observed in aged rats upon consuming plum juice [72]. Kuo et al. investigated effect of a cholesterol rich diet fortified with polyphenols from Oriental plums (Prunus salicina) on cognitive function. The researchers reached conclusion that the cholesterol rich diet per se resulted in outstanding cognitive decline, which was escorted by a superbly elevated mRNA expression of Cyp46, BACE1, A $\beta$, and 24-hydroxycholesterol within the brain cortex and hippocampus. Nevertheless, all of these factors were nonsignificantly increased in the high oriental plum group (HOP) against control group. Thus, addition of 


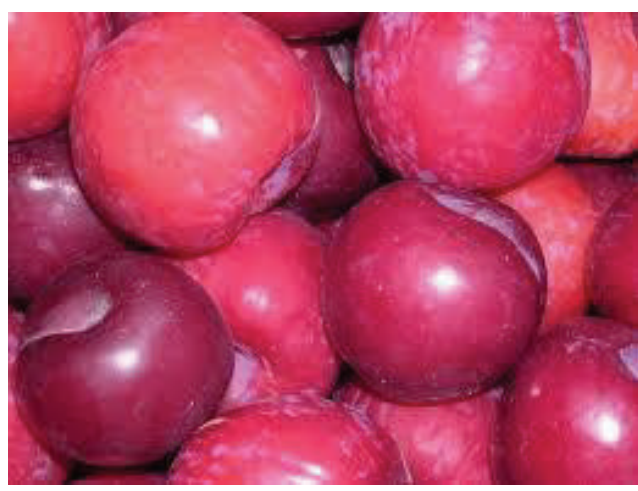

(a)

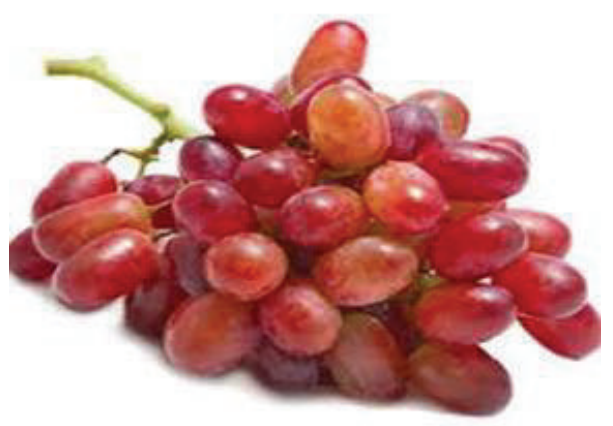

(c)

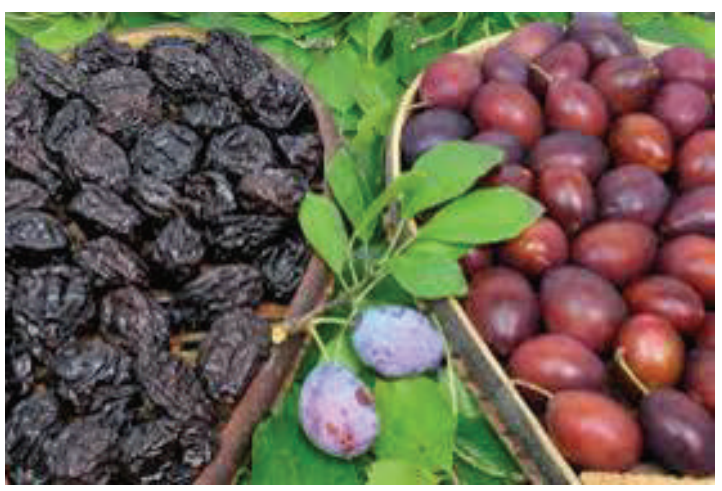

(b)



(d)

FIGURE 4: Structure of nutraceutical fruits for brain health: (a) plumes, (b) prunes, (c) red grapes, and (d) pomegranate.

polyphenol-fortified Oriental plum to a cholesterol rich diet may alleviate few of the manifestations of neurodegenerative disorders [73]. The fruits like blueberries, kiwis, plums, and apples have chlorogenic acid. The resveratrol, principal stilbene, may be occurring in the cis or trans configurations, either glucosylated (piceid) or in lesser amounts as the parent molecule of a class of polymers like viniferine, pallidol, or ampelopsin A. The dietary sources of resveratrol are grapes, wine, and peanuts [74].

2.8. Prunes. A prune (Figure 4(b)) is a dried plum of any cultivar, mostly Prunus domestica or European Plum. The use of the term for fresh fruit is obsolete except when applied to varieties grown for drying [75]. The presence of appreciable concentrations of vital nutrients such as carbohydrates, vitamins, and minerals renders prunes as healthy food. The medicinal significance of prunes and their products is also reported [76]. Prunes provide main nutrients, embracing carbohydrates, many amino acids, vitamin A, vitamin Bcomplex, vitamin $\mathrm{K}$, potassium, calcium, magnesium, zinc, copper, manganese, selenium, boron, and dietary fibers. The soluble fraction $(80 \%)$ having pectin, hemicellulose, cellulose, and lignins form prunes fiber. The total dietary fibers are enhanced upon drying [77].

The anxiolytic effect of chlorogenic acid, in a dose of $20 \mathrm{mg} / \mathrm{Kg}$, has been demonstrated in mouse models of anxiety, which may be via the activation of benzodiazepine receptors [78]. The pathogenesis of anxiety conditions has recently been found to implicate role of oxidative stress in brain. The presence of chlorogenic acid and ability to enhance antioxidant protection make prunes promising in anxiety disorders [79].

2.9. Red Grapes. The investigations have revealed that manifestations of cancer, heart disease, degenerative nerve disease, viral infections, and Alzheimer's disease are inhibited by phytochemicals present in grapes [like resveratrol (a polyphenol)] [80]. A common activity of resveratrol is responsible for defense of genome via antioxidant activity [81]. In laboratory research using mice, resveratrol is transcriptionally superimposed with the fruitful outcomes of calorie reduction in heart, skeletal muscle, and brain. The dietary measures block gene expression related to heart and skeletal muscle aging and check age-linked heart failure [82].

Globally grape (Figure 4(c)) is one of the most generally eaten fruits. It possesses a number of biological activities, owing to its high polyphenol components, and majority of them are present in its seeds (60-70\%) and skin (30\%). Nevertheless, huge amounts of grape seed wastes resulted annually by the food processing industry, wine, juice, and so forth [83]. Polyphenols from grape seeds may check oxidative destruction to cellular DNA in vitro [84, 85]. Guo et al. [86] investigated the probable shielding outcomes of grape seed oligomer and polymer procyanidin fractions 
against ethanol-stimulated toxicity. The findings showed that ethanol might trigger region-selective oxidative DNA loss in the cerebellum and hippocampus being more susceptible; however, consumption of grape seed procyanidins or other natural antioxidants could safeguard the brain against ethanol-induced genotoxicity.

2.10. Pomegranates. The Carthage where the finest pomegranates (Figure $4(\mathrm{~d})$ ) were recognized to grow was assigned genus Punica (its roman name) for pomegranate. The French call pomegranate as grenade whereas the Spanish utter it granada, and verbatim it means seeded (granatus) apple (pomum). The pomegranate (Punica granatum) is a deciduous shrub or stout tree, with height of 5-8 m (16 and $26 \mathrm{ft}$ ) [87]. The edible seeds of pomegranate are a brilliant source of dietary fiber ( $20 \% \mathrm{DV})$. The nutritional benefits offered by the seed fiber and micronutrients are wasted by consumers who opt to discard the seeds. The ingredients such as punicic acid (65.3\%), palmitic acid (4.8\%), stearic acid (2.3\%), oleic acid (6.3\%), and linoleic acid (6.6\%) are contained in pomegranate seed oil [88]. The most common phytochemicals in pomegranate juice are polyphenols, encompassing the hydrolyzable tannins known as ellagitannins produced when ellagic acid and/or gallic acid attach with a carbohydrate to yield pomegranate ellagitannins, also called punicalagins [89].

The neuroprotective features of pomegranate polyphenols were assessed in an animal model of Alzheimer's disease. Transgenic mice with Alzheimer's mimicking pathogenesis treated with pomegranate juice showed 50-percent fewer deposition of soluble amyloid-beta and few hippocampal amyloid accumulation than mice consuming sugar water, proposing that pomegranate juice can be neuroprotective. Animals too showed better learning of water maze accomplishments and swam faster than control animals [90]. The pregnant mice were provided pomegranate juice in drinking water disclosing that neonatal offspring being exposed to experimentally stimulated hypoxic-ischemic (HI) brain injury had superbly lesser degree of brain tissue damage (64\% decrease) and outstandingly reduced hippocampal caspase-3 activity (84\% decrease) in comparison with neonates having experimentally induced HI brain injury from dams who were given a control drink [91, 92]. These findings advise that pomegranate juice possesses an antioxidant-governed neuroprotective activity transferred from mother to neonate.

The inhibition of serum angiotensin converting enzyme (ACE) and reduction in systolic blood pressure in hypertensive patients were observed by intake of pomegranate juice as revealed by a small clinical trial. Ten hypertensive individuals (aged 62-77; seven men and three women) were provided $50 \mathrm{~mL} /$ day pomegranate juice having $1.5 \mathrm{mmol}$ total polyphenols for two weeks. Two of 7 men patients were diabetic too and two were hyperlipidemic as well. Seven of 10 subjects $(70 \%)$ perceived a 36 -percent mean reduction in serum ACE function and a tiny, but superb, 5-percent lowering of systolic blood pressure [93]. The dietary intake of antioxidants alleviates the danger of Alzheimer's disease as evident from numerous studies. Yet, more experiments are required to devise firm conclusions on the prophylactic effect of antioxidants [94]. Naveen et al. studied antidepression influence of polyphenols and omega-3 fatty acid from pomegranate peel and flax seed in mice subjected to chronic slight stress and summarized that the polyphenols from flax seed having omega-3 fatty acids were able to decrease all the chronic mild stress (CMS) outcomes examined in comparison with polyphenols from pomegranate peel [95]. Subash and colleagues investigated that pomegranate from Oman decreases the brain oxidative loss in transgenic mouse model of Alzheimer's disease (AD) and proposed that the therapeutic caliber of $4 \%$ pomegranate in the treatment of $\mathrm{AD}$ might be related to combating the oxidative stress by the occurrence of active phytochemicals in it [96].

\section{Conclusion}

The fruit and fruit juice would impart beneficial effect on brain functioning. The chemical contents have properties to alleviate the harmful effect of disease by reducing the oxidation stress or by other mechanisms. The influences of dietary factors upon neuronal process and synaptic flexibility have exhibited few of the essential underlying mechanisms for the role of diet in maintaining brain health and mental activity. The more investigations are warranted to elucidate the role of phytoconstituents in therapeutics of brain disorders.

\section{Conflict of Interests}

The authors declare that they have no conflict of interests.

\section{References}

[1] J. C. McCann and B. N. Ames, "Is docosahexaenoic acid, an n-3 long-chain polyunsaturated fatty acid, required for development of normal brain function? An overview of evidence from cognitive and behavioral tests in humans and animals," The American Journal of Clinical Nutrition, vol. 82, no. 2, pp. 281-295, 2005.

[2] A. Wu, Z. Ying, and F. Gomez-Pinilla, "Omega-3 fatty acids supplementation restores mechanisms that maintain brain homeostasis in traumatic brain injury," Journal of Neurotrauma, vol. 24, no. 10, pp. 1587-1595, 2007.

[3] C. E. Greenwood and G. Winocur, "High-fat diets, insulin resistance and declining cognitive function," Neurobiology of Aging, vol. 26, no. 1, supplement, pp. 42-45, 2005.

[4] R. Molteni, R. J. Barnard, Z. Ying, C. K. Roberts, and F. GómezPinilla, "A high-fat, refined sugar diet reduces hippocampal brain-derived neurotrophic factor, neuronal plasticity, and learning," Neuroscience, vol. 112, no. 4, pp. 803-814, 2002.

[5] F. Gómez-Pinilla, "Brain foods: the effects of nutrients on brain function," Nature Reviews Neuroscience, vol. 9, no. 7, pp. 568578, 2008.

[6] E. K. Kalra, "Nutraceutical-definition and introduction," AAPS PharmSci, vol. 5, no. 3, pp. 27-28, 2003.

[7] R. K. Keservani, R. K. Kesharwani, N. Vyas, S. Jain, R. Raghuvanshi, and A. K. Sharma, "Nutraceutical and functional food as future food: a review," Der Pharmacia Lettre, vol. 2, pp. 106-116, 2010. 
[8] International Food Information Council (IFIC), Functional Foods Now, Washington, DC, USA, 1999.

[9] A. G. Chintale, V. S. Kadam, R. S. Sakhare, G. O. Birajdar, and D. N. Nalwad, "Role of nutraceuticals in various diseases: a comprehensive review," International Journal of Research in Pharmacy and Chemistry, vol. 3, no. 2, pp. 290-299, 2013.

[10] C. L. Davis and S. Cooper, "Fitness, fatness, cognition, behavior, and academic achievement among overweight children: do cross-sectional associations correspond to exercise trial outcomes?" Preventive Medicine, vol. 52, supplement, pp. S65-S69, 2011.

[11] Y. Taki, H. Hashizume, Y. Sassa et al., "Breakfast staple types affect brain gray matter volume and cognitive function in healthy children," PLoS ONE, vol. 5, no. 12, Article ID e15213, pp. 1-8, 2010.

[12] A. Hoyland, L. Dye, and C. L. Lawton, "A systematic review of the effect of breakfast on the cognitive performance of children and adolescents," Nutrition Research Reviews, vol. 22, no. 2, pp. 220-243, 2009.

[13] M. Papp, E. Panconi, and P. Gruca, "Effects of the novel antidepressant milnacipran in a chronic mild stress model of depression," Drug Development Research, vol. 61, no. 2, pp. 101106, 2004.

[14] S. G. Kornstein and R. K. Schneider, "Clinical features of treatment-resistant depression," Journal of Clinical Psychiatry, vol. 62, pp. 18-25, 2001.

[15] J. Lenzer, "Antidepressants double suicidality in children, says FDA," The British Medical Journal, vol. 332, no. 7542, article 626, 2006.

[16] M. Stone, T. Laughren, M. L. Jones et al., "Risk of suicidality in clinical trials of antidepressants in adults: analysis of proprietary data submitted to US Food and Drug Administration," The British Medical Journal, vol. 339, article b2880, 2009.

[17] B. L. Plassman, J. W. Williams Jr., J. R. Burke, T. Holsinger, and S. Benjamin, "Systematic review: factors associated with risk for and possible prevention of cognitive decline in later life," Annals of Internal Medicine, vol. 153, no. 3, pp. 182-193, 2010.

[18] P. B. Adams, S. Lawson, A. Sanigorski, and A. J. Sinclair, "Arachidonic acid to eicosapentaenoic acid ratio in blood correlates positively with clinical symptoms of depression," Lipids, vol. 31, no. 1, pp. S157-S161, 1996.

[19] M. Peet, J. D. E. Laugharne, J. Mellor, and C. N. Ramchand, "Essential fatty acid deficiency in erythrocyte membranes from chronic schizophrenic patients, and the clinical effects of dietary supplementation," Prostaglandins Leukotrienes and Essential Fatty Acids, vol. 55, no. 1-2, pp. 71-75, 1996.

[20] J. R. Hibbeln, "Fish consumption and major depression," The Lancet, vol. 351, no. 9110, p. 1213, 1998.

[21] D. F. Horrobin, "Schizophrenia: the illness that made us human," Medical Hypotheses, vol. 50, no. 4, pp. 269-288, 1998.

[22] M. P. Freeman, J. R. Hibbeln, K. L. Wisner et al., "Omega-3 fatty acids: evidence basis for treatment and future research in psychiatry," Journal of Clinical Psychiatry, vol. 67, no. 12, pp. 1954-1967, 2006.

[23] A. Wu, Z. Ying, and F. Gómez-Pinilla, "Dietary omega-3 fatty acids normalize BDNF levels, reduce oxidative damage, and counteract learning disability after traumatic brain injury in rats," Journal of Neurotrauma, vol. 21, no. 10, pp. 1457-1467, 2004.

[24] R. K. Keservani, R. K. Kesharwani, A. K. Sharma, and M. F. Ahmad, "Stress, Parkinson's, Alzemer's disease: role of dietary supplements," in Nutraceuticals and Functional Foods in Human
Health and Disease Prevention, D. Bagchi, H. G. Preuss, and A. Swaroop, Eds., chapter 14, pp. 241-254, CRC Press, Taylor \& Francis, Boca Raton, Fla, USA, 2015.

[25] R. K. Keservani, S. Singh, V. Singh, R. K. Kesharwani, and A. K. Sharma, "Nutraceuticals and functional foods in the prevention of mental disorder," in Nutraceuticals and Functional Foods in Human Health and Disease Prevention, D. Bagchi, H. G. Preuss, and A. Swaroop, Eds., vol. 15, pp. 255-268, CRC Press, Taylor and Francis, Boca Rotan, Fla, USA, 2015.

[26] R. K. Keservani and A. K. Sharma, "Flavonoids: emerging trends and potential health benefits," Journal of Chinese Pharmaceutical Sciences, vol. 23, no. 12, pp. 815-822, 2014.

[27] C. E. Jarvis, "Seventy-two proposals for the conservation of types of selected linnaean generic names, the report of subcommittee $3 \mathrm{C}$ on the lectotypification of linnaean generic names," Taxon, vol. 41, no. 3, pp. 552-583, 1992.

[28] M. G. Miller and B. Shukitt-Hale, "Berry fruit enhances beneficial signaling in the brain," Journal of Agricultural and Food Chemistry, vol. 60, no. 23, pp. 5709-5715, 2012.

[29] B. L. Halvorsen, M. H. Carlsen, K. M. Phillips et al., "Content of redox-active compounds (i.e., antioxidants) in foods consumed in the United States," The American Journal of Clinical Nutrition, vol. 84, no. 1, pp. 95-135, 2006.

[30] R. D. Hancock and D. Stewart, "Enhancing the nutritional quality of fruit juices: advanced technologies for juice extraction and pasteurization," in Biotechnology in Functional Foods and Nutraceuticals, D. Bagchi, F. C. Lau, and D. K. Ghosh, Eds., pp. 463-482, CRC Press, Boca Raton, Fla, USA, 2010.

[31] N. Deighton, R. Brennan, C. Finn, and H. V. Davies, "Antioxidant properties of domesticated and wild Rubus species," Journal of the Science of Food and Agriculture, vol. 80, no. 9, pp. 1307-1313, 2000.

[32] J. P. E. Spencer, "The impact of fruit flavonoids on memory and cognition," British Journal of Nutrition, vol. 104, no. 3, pp. S40S47, 2010.

[33] B. Shukitt-Hale, R. L. Galli, V. Meterko et al., "Dietary supplementation with fruit polyphenolics ameliorates age-related deficits in behavior and neuronal markers of inflammation and oxidative stress," AGE, vol. 27, no. 1, pp. 49-57, 2005.

[34] W. D. Naumann, "Overview of the vaccinium industry in Western Europe," in Proceedings of the 5th International Symposium on Vaccinium Culture, K. A. Clayton-Greene, Ed., pp. 53-58, International Society for Horticultural Science (ISHS), Melbourne, Australia, January 1993.

[35] R. L. Prior, G. Cao, A. Martin et al., "Antioxidant capacity as influenced by total phenolic and anthocyanin content, maturity, and variety of vaccinium species," Journal of Agricultural and Food Chemistry, vol. 46, no. 7, pp. 2686-2693, 1998.

[36] National Health and Medical Research Council (NHMRC), "Nutrient relevance values for Australia and New Zealand: Including recommended dietary intakes," June 2015, https:// www.nhmrc.gov.au/_files_nhmrc/publications/attachments/n35 .pdf.

[37] A. B. Scholey, S. J. French, P. J. Morris, D. O. Kennedy, A. L. Milne, and C. F. Haskell, "Consumption of cocoa flavanols results in acute improvements in mood and cognitive performance during sustained mental effort," Journal of Psychopharmacology, vol. 24, no. 10, pp. 1505-1514, 2010.

[38] D. T. Field, C. M. Williams, and L. T. Butler, "Consumption of cocoa flavanols results in an acute improvement in visual and cognitive functions," Physiology and Behavior, vol. 103, no. 3-4, pp. 255-260, 2011. 
[39] R. Krikorian, M. D. Shidler, T. A. Nash et al., "Blueberry supplementation improves memory in older adults," Journal of Agricultural and Food Chemistry, vol. 58, no. 7, pp. 3996-4000, 2010.

[40] R. Krikorian, T. A. Nash, M. D. Shidler, B. Shukitt-Hale, and J. A. Joseph, "Concord grape juice supplementation improves memory function in older adults with mild cognitive impairment," British Journal of Nutrition, vol. 103, no. 5, pp. 730-734, 2010.

[41] C. Andres-Lacueva, B. Shukitt-Hale, R. L. Galli, O. Jauregui, R. M. Lamuela-Raventos, and J. A. Joseph, "Anthocyanins in aged blueberry-fed rats are found centrally and may enhance memory," Nutritional Neuroscience, vol. 8, no. 2, pp. 111-120, 2005.

[42] G. A. Manganaris, V. Goulas, A. R. Vicente, and L. A. Terry, "Berry antioxidants: small fruits providing large benefits," Journal of the Science of Food and Agriculture, vol. 94, no. 5, pp. 825-833, 2014.

[43] A. Basu, A. Nguyen, N. M. Betts, and T. J. Lyons, "Strawberry as a functional food: an evidence-based review," Critical Reviews in Food Science and Nutrition, vol. 54, no. 6, pp. 790-806, 2014.

[44] G. Cao, C. P. Verdon, A. H. B. Wu, H. Wang, and R. L. Prior, "Automated assay of oxygen radical absorbance capacity with the COBAS FARA II," Clinical Chemistry, vol. 41, no. 12, pp. 1738-1744, 1995.

[45] G. Cao, E. Sofic, and R. L. Prior, "Antioxidant capacity of tea and common vegetables," Journal of Agricultural and Food Chemistry, vol. 44, no. 11, pp. 3426-3431, 1996.

[46] H. Wang, G. Cao, and R. L. Prior, "Total antioxidant capacity of fruits," Journal of Agricultural and Food Chemistry, vol. 44, no. 3, pp. 701-705, 1996.

[47] S. M. Hannum, "Potential impact of strawberries on human health: a review of the science," Critical Reviews in Food Science and Nutrition, vol. 44, no. 1, pp. 1-17, 2004.

[48] A. Collie and G. Morley, "Do polyphenols affect human cognitive function?" Current Topics in Nutraceutical Research, vol. 5, no. 4, pp. 145-148, 2007.

[49] E. Carvalho, P. Franceschi, A. Feller, L. Palmieri, R. Wehrens, and S. Martens, "A targeted metabolomics approach to understand differences in flavonoid biosynthesis in red and yellow raspberries," Plant Physiology and Biochemistry, vol. 72, pp. 7986, 2013.

[50] S. P. Mazur, A. Nes, A.-B. Wold, S. F. Remberg, and K. Aaby, "Quality and chemical composition of ten red raspberry (Rubus idaeus L.) genotypes during three harvest seasons," Food Chemistry, vol. 160, pp. 233-240, 2014.

[51] E. Carvalho, P. D. Fraser, and S. Martens, "Carotenoids and tocopherols in yellow and red raspberries," Food Chemistry, vol. 139, no. 1-4, pp. 744-752, 2013.

[52] A. R. A. Ladiwala, M. Mora-Pale, J. C. Lin et al., "Polyphenolic glycosides and aglycones utilize opposing pathways to selectively remodel and inactivate toxic oligomers of amyloid beta," ChemBioChem, vol. 12, no. 11, pp. 1749-1758, 2011.

[53] F. C. Lau, D. F. Bielinski, and J. A. Joseph, "Inhibitory effects of blueberry extract on the production of inflammatory mediators in lipopolysaccharide-activated BV2 microglia," Journal of Neuroscience Research, vol. 85, no. 5, pp. 1010-1017, 2007.

[54] R. Krikorian, E. L. Boespflug, D. E. Fleck et al., "Concord grape juice supplementation and neurocognitive function in human aging," Journal of Agricultural and Food Chemistry, vol. 60, no. 23, pp. 5736-5742, 2012.
[55] B. Gonçalves, C. M. Correia, A. P. Silva, E. A. Bacelar, A. Santos, and J. M. Moutinho-Pereira, "Leaf structure and function of sweet cherry tree (Prunus avium L.) cultivars with open and dense canopies," Scientia Horticulturae, vol. 116, no. 4, pp. 381387, 2008.

[56] W. R. Pigeon, M. Carr, C. Gorman, and M. L. Perlis, "Effects of a tart cherry juice beverage on the sleep of older adults with insomnia: a pilot study," Journal of Medicinal Food, vol. 13, no. 3, pp. 579-583, 2010.

[57] H. R. Schumacher, S. Pullman-Mooar, S. R. Gupta, J. E. Dinnella, R. Kim, and M. P. McHugh, "Randomized doubleblind crossover study of the efficacy of a tart cherry juice blend in treatment of osteoarthritis (OA) of the knee," Osteoarthritis and Cartilage, vol. 21, no. 8, pp. 1035-1041, 2013.

[58] D. A. J. Connolly, M. P. McHugh, and O. I. Padilla-Zakour, "Efficacy of a tart cherry juice blend in preventing the symptoms of muscle damage," British Journal of Sports Medicine, vol. 40, no. 8, pp. 679-683, 2006.

[59] J. J. Matchynski, S. A. Lowrance, C. Pappas et al., "Combinatorial treatment of tart cherry extract and essential fatty acids reduces cognitive impairments and inflammation in the mu-p75 saporin-induced mouse model of Alzheimer's disease," Journal of Medicinal Food, vol. 16, no. 4, pp. 288-295, 2013.

[60] T. Tsuda, M. Watanabe, K. Ohshima et al., "Antioxidative activity of the anthocyanin pigments cyanidin 3-O- $\beta$-D-glucoside and cyanidin," Journal of Agricultural and Food Chemistry, vol. 42, no. 11, pp. 2407-2410, 1994.

[61] T. Tsuda, F. Horio, J. Kitoh, and T. Osawa, "Protective effects of dietary cyanidin 3-O- $\beta$-D-glucoside on liver ischemiareperfusion injury in rats," Archives of Biochemistry and Biophysics, vol. 368, no. 2, pp. 361-366, 1999.

[62] D.-O. Kim, J. H. Ho, J. K. Young, S. Y. Hyun, and C. Y. Lee, "Sweet and sour cherry phenolics and their protective effects on neuronal cells," Journal of Agricultural and Food Chemistry, vol. 53, no. 26, pp. 9921-9927, 2005.

[63] W. Reuther, H. J. Walter, and L. D. Batchelor, The Citrus Industry, vol. 1, Division of Agricultural Sciences, University of California, Berkeley, Calif, USA, 1967.

[64] J. K. Aschoff, S. Kaufmann, O. Kalkan, S. Neidhart, R. Carle, and R. M. Schweiggert, "In vitro bioaccessibility of carotenoids, flavonoids, and vitamin $\mathrm{C}$ from differently processed oranges and orange juices [Citrus sinensis (L.) Osbeck]," Journal of Agricultural and Food Chemistry, vol. 63, no. 2, pp. 578-587, 2015.

[65] P. R. Perez-Cacho and R. L. Rouseff, "Fresh squeezed orange juice odor: a review," Critical Reviews in Food Science and Nutrition, vol. 48, no. 7, pp. 681-695, 2008.

[66] R. J. Kean, D. J. Lamport, G. F. Dodd et al., "Chronic consumption of flavanone-rich orange juice is associated with cognitive benefits: an 8-wk, randomized, double-blind, placebocontrolled trial in healthy older adults," The American Journal of Clinical Nutrition, vol. 101, no. 3, pp. 506-514, 2015.

[67] D. Mischoulon and M. F. Raab, "The role of folate in depression and dementia," Journal of Clinical Psychiatry, vol. 68, supplement 10, pp. 28-33, 2007.

[68] V. Herbert, "Experimental nutritional folate deficiency in man," Transactions of the Association of American Physicians, vol. 75, pp. 307-320, 1962.

[69] J. Durga, M. P. van Boxtel, E. G. Schouten et al., "Effect of 3-year folic acid supplementation on cognitive function in older adults in the FACIT trial: a randomised, double blind, controlled trial," The Lancet, vol. 369, no. 9557, pp. 208-216, 2007. 
[70] D. Potter, T. Eriksson, R. C. Evans et al., "Phylogeny and classification of Rosaceae," Plant Systematics and Evolution, vol. 266, no. 1-2, pp. 5-43, 2007.

[71] D.-O. Kim, O. K. Chun, Y. J. Kim, H.-Y. Moon, and C. Y. Lee, "Quantification of polyphenolics and their antioxidant capacity in fresh plums," Journal of Agricultural and Food Chemistry, vol. 51, no. 22, pp. 6509-6515, 2003.

[72] B. Shukitt-Hale, W. Kalt, A. N. Carey, M. Vinqvist-Tymchuk, J. McDonald, and J. A. Joseph, "Plum juice, but not dried plum powder, is effective in mitigating cognitive deficits in aged rats," Nutrition, vol. 25, no. 5, pp. 567-573, 2009.

[73] P. H. Kuo, C. I. Lin, Y. H. Chen, W. C. Chiu, and S. H. Lin, "A high-cholesterol diet enriched with polyphenols from Oriental plums (Prunus salicina) improves cognitive function and lowers brain cholesterol levels and neurodegenerative-related protein expression in mice," British Journal of Nutrition, vol. 113, no. 10, pp. 1550-1557, 2015.

[74] D. Vauzour, "Dietary polyphenols as modulators of brain functions: biological actions and molecular mechanisms underpinning their beneficial effects," Oxidative Medicine and Cellular Longevity, vol. 2012, Article ID 914273, 16 pages, 2012.

[75] Q. Jabeen and N. Aslam, "The pharmacological activities of prunes: the dried plums," Journal of Medicinal Plants Research, vol. 5, no. 9, pp. 1508-1511, 2011.

[76] T. S. C. Li, Vegetables and Fruits: Nutritional and Therapeutic Values, vol. 169, 195, 198, Taylor and Francis Group, Boca Raton, Fla, USA, 2008.

[77] M. Siddiq, "Plums and prunes," in Handbook of Fruits and Fruit Processing, Y. H. Hui, Ed., pp. 553-564, Blackwell Publishing Professional, Iowa City, Iowa, USA, 2006.

[78] J. Bouayed, H. Rammal, A. Dicko, C. Younos, and R. Soulimani, "Chlorogenic acid, a polyphenol from Prunus domestica (Mirabelle), with coupled anxiolytic and antioxidant effects," Journal of the Neurological Sciences, vol. 262, no. 1-2, pp. 77-84, 2007.

[79] J. Bouayed, H. Rammal, and R. Soulimani, "Oxidative stress and anxiety, relationship and cellular pathways," Oxidative Medicine and Cellular Longevity, vol. 2, pp. 63-67, 2009.

[80] S. Shankar, G. Singh, and R. K. Srivastava, "Chemoprevention by resveratrol: molecular mechanisms and therapeutic potential," Frontiers in Bioscience: A Journal and Virtual Library, vol. 12, no. 12, pp. 4839-4854, 2007.

[81] S. A. Gatz and L. Wiesmüller, "Take a break-resveratrol in action on DNA," Carcinogenesis, vol. 29, no. 2, pp. 321-332, 2008.

[82] J. L. Barger, T. Kayo, J. M. Vann et al., "A low dose of dietary resveratrol partially mimics caloric restriction and retards aging parameters in mice," PLoS ONE, vol. 3, no. 6, Article ID e2264, 2008.

[83] M. A. Yoo, H. K. Chung, and M. H. Kang, "Evaluation of physicochemical properties in different cultivar grape seed waste," Food Science and Biotechnology, vol. 13, pp. 26-29, 2004.

[84] P. H. Fan and H. X. Lou, "Isolation and structure identification of grape seed polyphenols and its effects on oxidative damage to cellular DNA," Yao Xue Xue Bao, vol. 39, no. 11, pp. 869-875, 2004.

[85] M. Balu, P. Sangeetha, G. Murali, and C. Panneerselvam, "Modulatory role of grape seed extract on age-related oxidative DNA damage in central nervous system of rats," Brain Research Bulletin, vol. 68, no. 6, pp. 469-473, 2006.

[86] L. Guo, H. W. Li, B. Sun et al., "Direct in vivo evidence of protective effects of grape seed procyanidin fractions and other antioxidants against ethanol-induced oxidative DNA damage in mouse brain cells," Journal of Agricultural and Food Chemistry, vol. 55, no. 14, pp. 5881-5891, 2007.

[87] H. LaRue and H. James, "Growing Pomegranates in California," California Agriculture and Natural Resources, 2007.

[88] S. Y. Schubert, E. P. Lansky, and I. Neeman, "Antioxidant and eicosanoid enzyme inhibition properties of pomegranate seed oil and fermented juice flavonoids," Journal of Ethnopharmacology, vol. 66, no. 1, pp. 11-17, 1999.

[89] R. P. Singh, K. N. C. Murthy, and G. K. Jayaprakasha, "Studies on the antioxidant activity of pomegranate (Punica granatum) peel and seed extracts using in vitro models," Journal of Agricultural and Food Chemistry, vol. 50, no. 1, pp. 81-86, 2002.

[90] R. E. Hartman, A. Shah, A. M. Fagan et al., "Pomegranate juice decreases amyloid load and improves behavior in a mouse model of Alzheimer's disease," Neurobiology of Disease, vol. 24, no. 3, pp. 506-515, 2006.

[91] D. J. Loren, N. P. Seeram, R. N. Schulman, and D. M. Holtzman, "Maternal dietary supplementation with pomegranate juice is neuroprotective in an animal model of neonatal hypoxicischemic brain injury," Pediatric Research, vol. 57, no. 6, pp. 858864, 2005.

[92] T. West, M. Atzeva, and D. M. Holtzman, "Pomegranate polyphenols and resveratrol protect the neonatal brain against hypoxic-ischemic injury," Developmental Neuroscience, vol. 29, no. 4-5, pp. 363-372, 2007.

[93] M. Aviram and L. Dornfeld, "Pomegranate juice consumption inhibits serum angiotensin converting enzyme activity and reduces systolic blood pressure," Atherosclerosis, vol. 158, no. 1, pp. 195-198, 2001.

[94] B. P. F. Rutten, H. W. M. Steinbusch, H. Korr, and C. Schmitz, "Antioxidants and Alzheimer's disease: from bench to bedside (and back again)," Current Opinion in Clinical Nutrition \& Metabolic Care, vol. 5, no. 6, pp. 645-651, 2002.

[95] S. Naveen, M. Siddalingaswamy, D. Singsit, and F. Khanum, "Anti-depressive effect of polyphenols and omega-3 fatty acid from pomegranate peel and flax seed in mice exposed to chronic mild stress," Psychiatry and Clinical Neurosciences, vol. 67, no. 7, pp. 501-508, 2013.

[96] S. Subash, M. Essa, A. Al-Asmi et al., "Pomegranate from oman alleviates the brain oxidative damage in transgenic mouse model of alzheimer's disease," Journal of Traditional and Complementary Medicine, vol. 4, no. 4, pp. 232-238, 2014. 


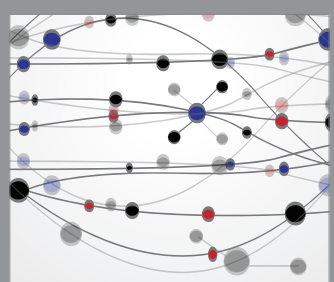

The Scientific World Journal
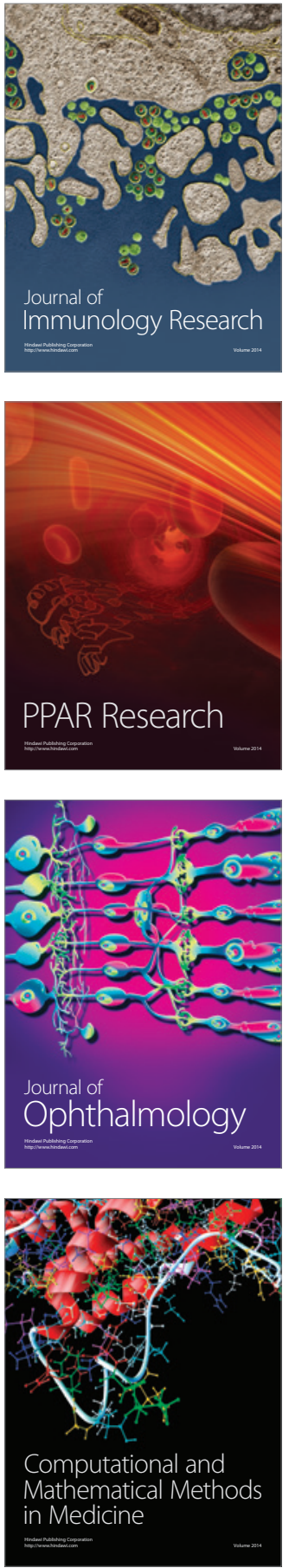

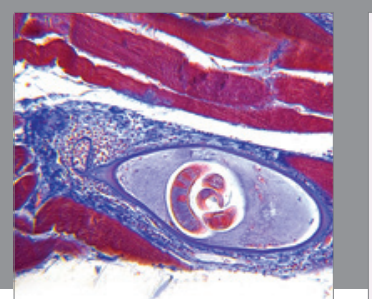

Gastroenterology Research and Practice

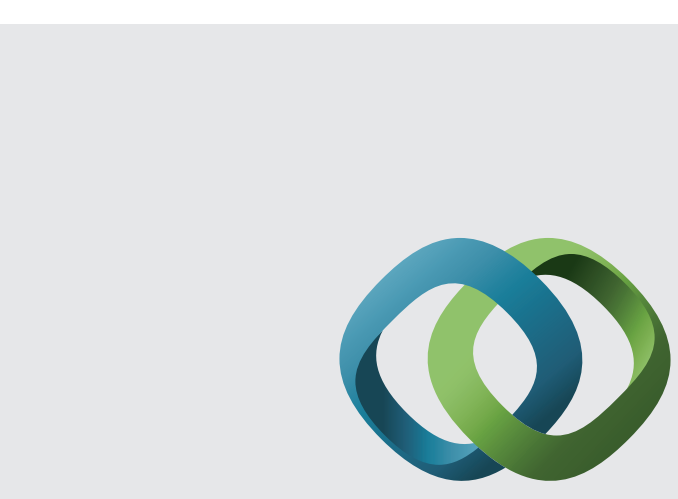

\section{Hindawi}

Submit your manuscripts at

http://www.hindawi.com
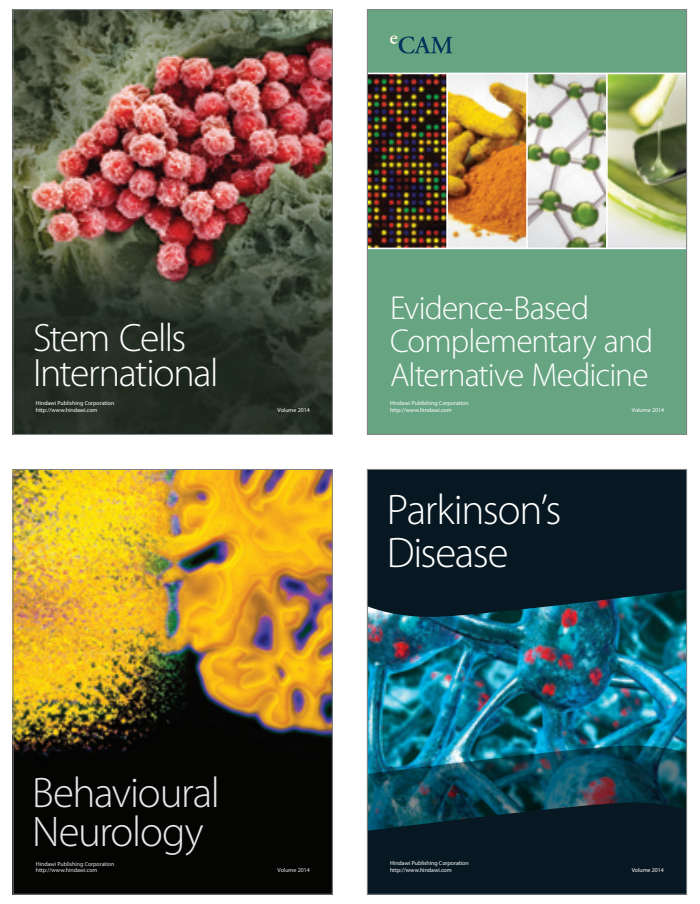


Disease Markers
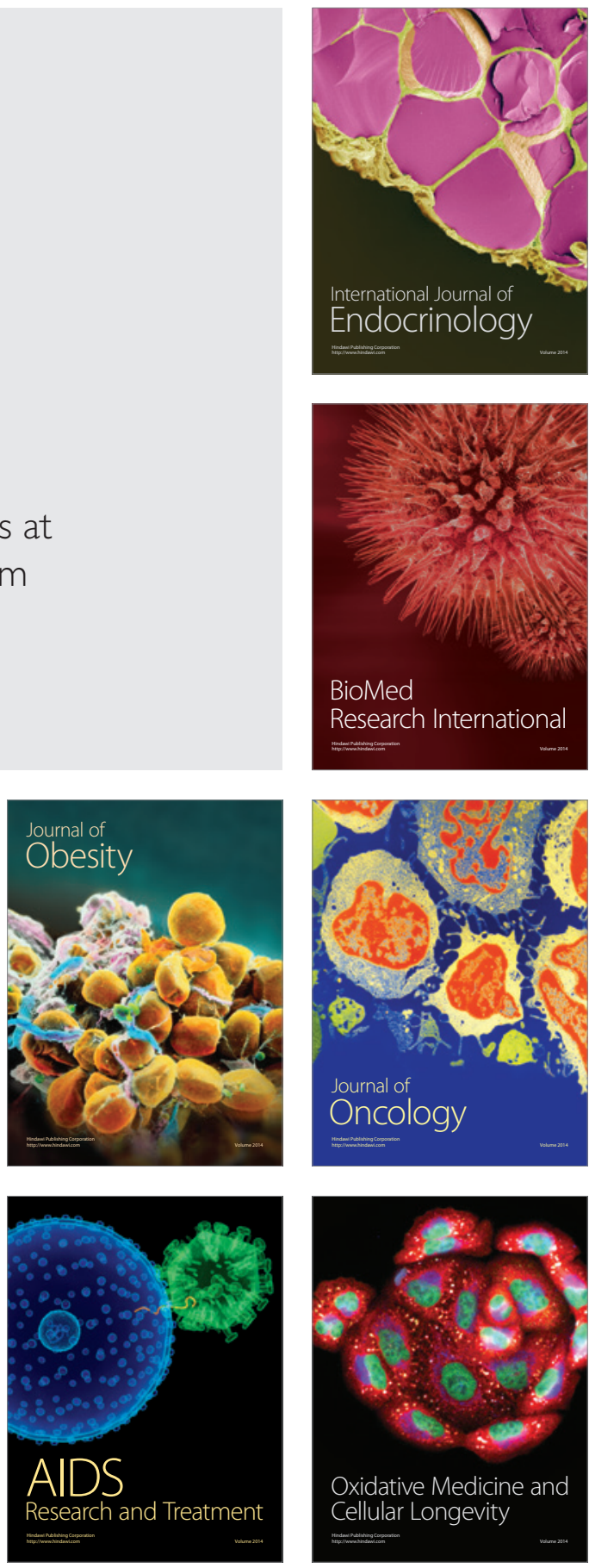